\title{
Neurologic outcome after cardiopulmonary bypass with deep hypothermic circulatory arrest in rats: Description of a new model
}

Bettina Jungwirth, MD, ${ }^{a}$ G. Burkhard Mackensen, MD, ${ }^{a, b}$ Manfred Blobner, MD, ${ }^{a}$ Frauke Neff, MD, ${ }^{d}$ Bruno Reichart, MD, ${ }^{c}$ Eberhard F. Kochs, MD, ${ }^{a}$ and Georg Nollert, MD, FAHA ${ }^{c}$

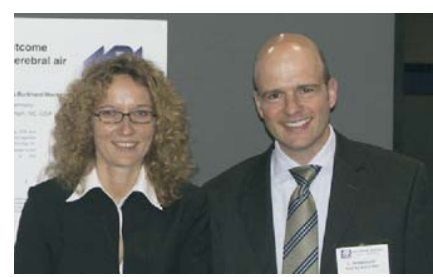

Drs B. Jungwirth and G. B. Mackensen (left to right)
From Klinik für Anaesthesiologie ${ }^{\mathrm{a}}$ and Institut für Allgemeine Pathologie und Pathologische Anatomie, ${ }^{\mathrm{d}}$ Technische Universität München, Klinikum rechts der Isar, Munich, Germany; the Department of Anesthesiology, Duke University Medical Center, ${ }^{\mathrm{b}}$ Durham, NC; and Herzchirurgische Klinik im Klinikum Großhadern, LudwigsMaximilian Universität München, ${ }^{\mathrm{c}}$ Munich, Germany

This work was supported in part by the Deutsche Forschungsgemeinschaft (NO 344/3-1).

Received for publication July 29, 2005; revisions received Oct 27, 2005; accepted for publication Nov 8, 2005.

Address for reprints: G. Burkhard Mackensen, MD, Department of Anesthesiology, Division of Cardiothoracic Anesthesiology and Critical Care Medicine, Duke University Medical Center, Durham, NC 27710 (E-mail: b.mackensen@duke.edu).

J Thorac Cardiovasc Surg 2006;131:805-12 0022-5223/\$32.00

Copyright (๑) 2006 by The American Association for Thoracic Surgery

doi:10.1016/j.jtcvs.2005.11.017
Objective: Neurodevelopmental impairments after repair of congenital heart disease with cardiopulmonary bypass and deep hypothermic circulatory arrest continue to affect the lives of children. To date, the preclinical investigation of cerebral injury mechanisms related to deep hypothermic circulatory arrest has been restricted to expensive, personnel-demanding, and cumbersome large-animal models without validated neuropsychologic assessment. We aimed to establish a rodent recovery model of deep hypothermic circulatory arrest to overcome these disadvantages.

Methods: Male rats $(\mathrm{n}=34)$ were cannulated for cardiopulmonary bypass, cooled to a rectal temperature of $16^{\circ} \mathrm{C}$ to $18^{\circ} \mathrm{C}$ within 30 minutes, and assigned to deep hypothermic circulatory arrest durations of $0,45,60,75,90(n=6$, respectively), or $105(\mathrm{n}=4)$ minutes. After rewarming within 40 minutes, animals were weaned from cardiopulmonary bypass at $35.5^{\circ} \mathrm{C}$. Neurologic and cognitive performance was assessed with the modified hole board test until postoperative day 14. Thereafter, brains were perfusion fixed and histologically analyzed.

Results: Logistic regression analyses identified dose-dependent associations between survival, neurologic or cognitive function, and duration of deep hypothermic circulatory arrest. Functional and histologic deficits were detectable after clinically relevant deep hypothermic circulatory arrest durations. The overall neurologic function did not correlate with histologic outcome $(r=0.51, P>.05)$.

Conclusions: The current study presents a novel recovery model of cardiopulmonary bypass with deep hypothermic circulatory arrest in the rat. In contrast to studies in large animals, even clinically relevant deep hypothermic circulatory arrest durations up to 60 minutes resulted in detectable deficits. Consequently, this experimental model appears to be suitable to further elucidate the mechanisms associated with adverse cerebral outcome after cardiac surgery and deep hypothermic circulatory arrest and to investigate potential neuroprotective strategies.

$\Lambda$ lthough overall morbidity and mortality of children after repair of congenital heart disease with deep hypothermic circulatory arrest (DHCA) have been substantially improved, considerable neurologic and neurodevelopmental sequelae still affect this patient population. Preventing cerebral injury remains difficult because the underlying mechanisms are incompletely understood. Although several preoperative and intraoperative factors, including the use of DHCA, have been identified as risk factors for postoperative cerebral impairments, ${ }^{1-3}$ clinical studies have only recently contributed to reveal the underlying injury mechanisms. ${ }^{4}$ Therefore, an appropriate disease model of cardiopulmonary bypass (CPB) and DHCA is needed. ${ }^{5}$ To date, preclinical investigations of cerebral injury after DHCA have been restricted to large-animal models. These models all have certain disadvantages, drawbacks, and limitations, including significant costs, 

Abbreviations and Acronyms
$\mathrm{CPB}=$ cardiopulmonary bypass
DHCA $=$ deep hypothermic circulatory arrest
MAP $=$ mean arterial blood pressure
mHBT $=$ modified hole board test

logistic requirements, lack of suitable tests for the assessment of neurologic and neurocognitive function, and difficulties with long-term recovery. The rat is the most widely accepted animal to study cerebral injury, with various behavioral and cognitive tests available. Because a long-term recovery model of $\mathrm{CPB}$ in this species has recently been introduced, ${ }^{6}$ we sought to assess whether a clinically relevant recovery model of $\mathrm{CPB}$ and DHCA in the rat could be established to investigate basic mechanisms of cerebral injury.

The aims of the present study were to determine (1) whether DHCA in the rat could be performed mimicking current clinical standards and whether survival after different durations of DHCA is feasible; (2) whether exposure to different durations of DHCA affects postoperative neurologic, neurocognitive, or behavioral performance; and (3) whether these impairments are associated with histologic alterations.

\section{Methods}

All animals were treated in compliance with the "Principles of Laboratory Animal Care" formulated for the National Society for Medical Research and the "Guide for the Care and Use of Laboratory Animals" prepared by the National Academy of Science (National Institutes of Health publication no. 86-23, revised 1985). Experimental protocols were approved by the institutional animal care committee.

Male Sprague Dawley rats from Charles River Laboratories (Sulzfeld, Germany) were housed under standard laboratory conditions (12 hours light/12 hours dark, lights on at $12: 30 \mathrm{Am}, 22^{\circ} \mathrm{C}$, $60 \%$ humidity, and free access to water and standard rat chow) 3 weeks before the experiments to acclimate to the changed daynight rhythm. Nine days before surgical preparation, animals were housed in the modified hole board environment for habituation.

Rats were randomly assigned to 1 of 6 groups with different durations of DHCA. In the 0-minute DHCA group $(n=6)$ rats were cooled to a rectal temperature of $16^{\circ} \mathrm{C}$ to $18^{\circ} \mathrm{C}$ and immediately rewarmed over 40 minutes without any arrest time. Animals in the other 5 groups were cooled accordingly but subjected to either 45 minutes $(n=6), 60$ minutes $(n=6), 75$ minutes $(n=$ $6), 90$ minutes $(n=6)$, or 105 minutes $(n=4)$ of DHCA.

\section{Surgical Preparation}

Nonfasted rats $(356 \pm 19 \mathrm{~g}, 10$ weeks old) were cannulated for $\mathrm{CPB}$, as previously reported. ${ }^{6}$ In brief, surgical intervention was performed in anesthetized (2-2.5 Vol\% isoflurane), endotracheally intubated (14-gauge intravenous catheter), and mechanically ven- tilated ( $45 \% \mathrm{O}_{2} /$ balance $\mathrm{N}_{2}, \mathrm{PaCO}_{2}$ of $35-45 \mathrm{~mm} \mathrm{Hg}$ ) rats by using aseptic techniques. The tail artery was cannulated with a 20 -gauge catheter for aortic inflow. After the placement of the arterial catheter, rats were given $150 \mathrm{IU}$ of heparin and $5 \mu \mathrm{g}$ of fentanyl. Through the right external jugular vein, a $4.5 \mathrm{~F}$ multiorifice cannula was advanced into the right atrium for venous return. Mean arterial blood pressure (MAP) was monitored through the right superficial caudal epigastric artery. Baseline physiologic measurements, including MAP, pericranial and rectal temperature, and blood gases (Rapidlab 860 blood gas analyzer; Diamond Diagnostics, Holliston, Mass), were recorded 10 minutes before commencement of CPB. During surgical preparation, the temperature was allowed to decrease spontaneously; however, rectal temperatures of less than $34^{\circ} \mathrm{C}$ were avoided by warming the animals with heating blankets and a convective forced-air heating system (Warmtouch 5200; Nellcor, Hazelwood, Mo).

\section{CPB and DHCA}

The CPB circuit consisted of a venous reservoir, a peristaltic pump (Masterflex; Cole-Parmer Instrument Co, Vernon Hills, Ill), a specifically developed membrane oxygenator (prime volume of $4 \mathrm{~mL}$, gas exchange area of $\left.558 \mathrm{~cm}^{2}\right)$, an inline flow probe $(2 \mathrm{~N} 806$ flow probe and T208 volume flowmeter; Transonics Systems, Inc, Ithaca, NY), and an arterial inflow cannula, all of which were connected through 1.6-mm internal diameter silicone tubing (Tygon, Cole-Parmer Instrument Co). The CPB circuit was primed with $10 \mathrm{~mL}$ of $6 \%$ hetastarch. The small-volume oxygenator developed specifically for the use in rats is built of 2 Plexiglas shells $(12.8 \mathrm{~cm} \times 12.8 \mathrm{~cm} \times 2.7 \mathrm{~cm})$ carrying the diffusion membrane. The membrane consists of 3 layers of polypropylene hollow-fiber mats (Jostra AG, Hirrlingen, Germany) glued together in a crosswise fashion to improve oxygenation. The provided gas exchange area is $558 \mathrm{~cm}^{2}$. CPB was instituted at a flow rate of 160 to $180 \mathrm{~mL} \cdot \mathrm{kg}^{-1} \cdot \mathrm{min}^{-1}$ and was consecutively decreased by half during the cooling period. During CPB, the oxygenator received a gas mixture of $\mathrm{O}_{2}$ and variable concentrations of $\mathrm{CO}_{2}$ as arterial blood gases were controlled with the $\mathrm{pH}$-strategy ( $\mathrm{PaCO}_{2}$ of 31-40 $\mathrm{mm} \mathrm{Hg}$, temperature adjusted). The animals were cooled to a rectal temperature of $16^{\circ} \mathrm{C}$ to $18^{\circ} \mathrm{C}$ over 30 minutes by using a heat exchanger and topical cooling with ice bags and a cooling blanket. CPB was discontinued, and venous blood was drained to the reservoir. DHCA confirmed by asystole was maintained for $45,60,75,90$, or 105 minutes at $16^{\circ} \mathrm{C}$ to $18^{\circ} \mathrm{C}$. Animals subjected to 0 minutes of DHCA were immediately rewarmed without arrest. After DHCA, CPB was reinstituted, and rats were rewarmed to rectal temperatures of at least $35.5^{\circ} \mathrm{C}$ over $40 \mathrm{~min}$ utes; subsequently, $\mathrm{CPB}$ was terminated. During $\mathrm{CPB}$, the rats were anesthetized with $0.8 \%$ to $1 \%$ isoflurane, cisatracurium (1.6 $\mathrm{mg} / \mathrm{h}$ ), and repetitive boluses of $5 \mu \mathrm{g}$ of fentanyl, while anesthesia was discontinued during DHCA. During DHCA, animals were not ventilated, but during $\mathrm{CPB}$, a continuous positive airway pressure mode $\left(5 \mathrm{~cm} \mathrm{H}_{2} \mathrm{O}\right)$ with a fraction of inspired oxygen of 0.21 was applied to avoid atelectasis. After DHCA, bicarbonate was administered to correct acidosis. During rewarming, MAP was kept at greater than $50 \mathrm{~mm} \mathrm{Hg}$ with norepinephrine as soon as rectal temperatures of at least $30^{\circ} \mathrm{C}$ and blood flows of at least 150 $\mathrm{mL} \cdot \mathrm{min}^{-1} \cdot \mathrm{kg}^{-1}$ were achieved. 


\section{Recovery and Survival}

After decannulation, rats were maintained anesthetized with $1.0 \%$ to $1.5 \%$ isoflurane, intubated, and ventilated for 1 hour (rectal temperature of $36.5^{\circ} \mathrm{C}$ ). To increase the hematocrit value to greater than $30 \%$, the remaining blood in the CPB circuit was collected, centrifuged (2000 rpm for 10 minutes), and transfused to the animals. Bicarbonate, calcium, and glucose levels were monitored and administered as needed. Heparin-induced anticoagulation was not reversed by protamine. After spontaneous ventilation had resumed, animals were extubated and allowed to recover in an oxygen-enriched environment for 12 hours, with free access to water and food. During the first 6 hours of recovery, they were continuously observed to identify severe neurologic dysfunction, such as immediate signs of cerebral death (fixed pupils, no reaction to pain, and absence of spontaneous breathing), seizures, and inability to ambulate. Animals demonstrating signs of severe neurologic dysfunction were killed. All others were returned to their hole board cages at the first postoperative day and housed in familiar groups.

\section{Neurologic, Cognitive, and Behavioral Testing}

All neurologic, cognitive, and behavioral tests were performed by an investigator blinded to group assignment. On the preoperative, as well as on the first, second, third, and twelfth postoperative days, animals underwent standardized functional neurologic testing, as previously described (Table 1 ). ${ }^{7}$ In addition, cognitive and behavioral functions were assessed by the modified hole board test (mHBT), according to an established protocol. ${ }^{8,9}$ In brief, the rats were housed in an area divided into a home cage $(80 \times 60 \times 50$ $\mathrm{cm})$ and a test arena $(40 \times 60 \times 50 \mathrm{~cm})$ with the centrally placed hole board $(20 \times 40 \mathrm{~cm})$. Fifteen holes covered by lids were staggered on the board. After being opened, coil springs force the lids back to their original position. Three holes baited with puffed rice were marked with white tape. All holes were flavored with the aroma of black currants to cover the odor and smell of the puffed rice.

After habituation to the mHBT on postoperative days 2 and 3 , rats learned the test procedure over 6 consecutive days (learning period). Subsequent to a resting period of 4 days, memory function was assessed on postoperative day 14 (retest). Animals were tested in the mHBT for 3 trials daily, and the sequence of marked holes was randomly changed every day. Various cognitive, motor, and behavioral parameters were studied with the mHBT (Table 1).

\section{Histologic Examination}

After completion of the neurocognitive testing on the 14th postoperative day, animals were anesthetized with $5 \%$ isoflurane and underwent in situ brain fixation by a standardized intracardiac injection of $20 \mathrm{~mL}$ of saline, followed by $20 \mathrm{~mL}$ of paraformaldehyde (4\%). The brain was removed in toto, cut in 2-mm slices, and then embedded in paraffin. The first section $(10 \mu \mathrm{m})$ of each block was harvested and stained with hematoxylin and eosin to determine cell damage. All slides were scored by a neuropathologist blinded to the experimental groups. Five brain regions of each hemisphere were chosen for evaluation of neuronal cell damage: hippocampus, frontal cortex (motor area), cerebellar vermis, cingulate cortex (posterior part), and striatum (caudate putamen). Five high-magnification $(440 \times)$ fields per region were ex- amined by use of the following scores: 0 , fewer than 5 damaged neurons; 1,5 to 10 damaged neurons; 2, more than 10 damaged neurons; and 3, infarction. The score values for the single regions were summed to a total histologic score for each animal, with a maximum score of 150 (5 high-magnification fields $\times 3$ as worst score $\times 10$ brain regions) and a normal range of 0 to 12 taken from 6 healthy untreated rats (mean \pm 2 standard deviations).

\section{Statistics and Data Management}

Physiologic values were analyzed by use of general linear models with the between-groups factor DHCA duration, the within-groups factor time ${ }^{2}$, and their interaction term (time ${ }^{2} \times$ DHCA duration). Effects of time levels were analyzed quadratically, focusing on biphasic changes of all variables during the observation period. Once time $^{2} \times$ DHCA duration was significant $(P<.05)$, post-hoc values at certain times were analyzed by factorial analysis of variance, followed by Bonferroni $t$ tests.

Logistic regression analyses were performed with DHCA duration as the independent variable and survival, survival without motor deficit, or survival without cognitive deficits as dependent variables to analyze the effect of DHCA duration on outcome. Survival without the respective deficit was assumed if none of the tested qualities was out of its normal range (Table 1).

Additionally, functional outcome of surviving rats was correlated with the histologic outcome by Spearman rank correlation. Therefore, individual functional parameters were recorded as score values (maximum scores being the worst outcome) and summed to a total neurologic score (0-85) for each animal (Table 1).

\section{Results}

Three animals were excluded from further data analysis because of either insufficient venous return (1 animal in the 45-minute DHCA group) or cannulation problems (1 rat in the 60 -minute and 1 rat in the 75 -minute DHCA groups). These rats were replaced to keep sample size equal. Hemodynamic and physiologic values of rats are summarized in Table 2. Priming the circuit with $6 \%$ hetastarch led to a decrease in hemoglobin concentration from $14.7 \pm 0.3 \mathrm{~g} / \mathrm{dL}$ at baseline to $7.1 \pm 0.3 \mathrm{~g} / \mathrm{dL}$ during CPB. Retransfusion of red cells after $\mathrm{CPB}$ restored the hemoglobin concentration to $10.7 \pm 0.3 \mathrm{~g} / \mathrm{dL}$.

Survival was related to DHCA duration in a dose-dependent manner, with $50 \%$ survival at 83 minutes $(95 \%$ confidence interval, 71-99 minutes; Figure 1, A). All animals exposed to 105 minutes of DHCA showed immediate signs of brain death. In the 90-minute group, 2 rats were killed within the first postoperative hours because of severe cerebral injury, and 1 rat died during the first postoperative day because of gastrointestinal paresis. After initial survival, 3 animals in the 75-minute DHCA group died of intestinal dysfunction on the first, second, and fourth postoperative days, respectively. All remaining rats survived the entire recovery period until brain fixation at postoperative day 14 .

Motor function and neurocognitive outcome were affected by DHCA duration. With increasing DHCA durations, the percentage of animals without motor and cogni- 
TABLE 1. The whole test battery used in the current study for the assessment of motor, cognitive, behavioral, and sensory function after deep hypothermic circulatory arrest

\begin{tabular}{|c|c|c|c|c|c|c|c|c|c|c|}
\hline \multirow[b]{2}{*}{ Quality } & \multirow[b]{2}{*}{ Test } & \multicolumn{7}{|c|}{ Level of impairment } & \multirow[b]{2}{*}{ Score } & \multirow[b]{2}{*}{ Norma } \\
\hline & & 0 & 1 & 2 & 3 & 4 & 5 & 6 & & \\
\hline \multicolumn{11}{|l|}{ Motor function } \\
\hline Coordination & Missteps on beam & $1-3$ & $4-10$ & $11-20$ & $>20$ & unable & - & - & $0-4$ & 0 \\
\hline Physical strength & Time gripping a rope & $11-15 \mathrm{~s}$ & $6-10 s$ & $1-5 \mathrm{~s}$ & unable & - & - & - & $0-3$ & 0 \\
\hline Movement symmetry & $\begin{array}{l}\text { Observation of active } \\
\text { movement }\end{array}$ & Symmetric & $\begin{array}{l}\text { One-sided } \\
\text { weakness }\end{array}$ & Hemiplegia & - & - & - & - & $0-2$ & 0 \\
\hline Gait & Observation of gait & Normal & Ataxia & Circular motion & - & - & - & - & $0-2$ & 0 \\
\hline Fine-motor skill & $\begin{array}{l}\text { time needed for } 1 \\
\text { food intake (mHBT) }\end{array}$ & $<20 \mathrm{~s}$ & $20-30 \mathrm{~s}$ & $30-45 \mathrm{~s}$ & $>45 \mathrm{~s}$ & - & - & - & $0-3$ & 0 \\
\hline Dexterity & $\begin{array}{l}\text { Futile efforts to open } \\
\text { a baited hole } \\
\text { (mHBT) }\end{array}$ & 0 & 1 & 2 & $>2$ & - & - & - & $0-3$ & 0 \\
\hline Declarative memory & $\begin{array}{l}\text { Omission errors of } 3 \\
\text { trials }\end{array}$ & 0 & 1 & 2 & 3 & 4 & 5 & $>5$ & $0-6$ & 0 \\
\hline Working memory & $\begin{array}{l}\text { Repeated choices of } \\
3 \text { trials }\end{array}$ & 0 & 1 & 2 & 3 & 4 & 5 & $>5$ & $0-6$ & $0-1$ \\
\hline Cognitive performance & $\begin{array}{l}\text { Time needed to } \\
\text { complete } 3 \text { trials }\end{array}$ & $<200 \mathrm{~s}$ & $200-399 \mathrm{~s}$ & $400-599 \mathrm{~s}$ & $600-799 \mathrm{~s}$ & $800-999 \mathrm{~s}$ & $1000-1199 \mathrm{~s}$ & $>2000 \mathrm{~s}$ & $0-6$ & $0-1$ \\
\hline \multicolumn{11}{|c|}{ Behavior (assessed with the mHBT) } \\
\hline \multirow[t]{3}{*}{ Anxiety } & $\begin{array}{l}\text { Time spent on board } \\
\text { per trial }\end{array}$ & $>15 \%$ & $6 \%-15 \%$ & $<6 \%$ & - & - & - & - & $0-2$ & 0 \\
\hline & $\begin{array}{l}\text { Latency to first enter } \\
\text { the board }\end{array}$ & $<10 \mathrm{~s}$ & $>10 \mathrm{~s}$ & - & - & - & - & - & $0-1$ & 0 \\
\hline & No. of board entries & $>1$ & No entries & - & - & - & - & - & $0-1$ & 0 \\
\hline Locomotor activity & No. of line crossings & $<3$ & 3-4 & 4-5 & $>5$ & - & - & - & $0-3$ & 0 \\
\hline \multicolumn{11}{|l|}{ Sensory function } \\
\hline Vision & $\begin{array}{l}\text { Reaction to a falling } \\
\text { cotton wool }\end{array}$ & Both sides & Only one side & No reaction & - & - & - & - & $0-2$ & 0 \\
\hline Hearing & Reaction to a whistle & Yes & No & - & - & - & - & - & $0-1$ & 0 \\
\hline Body proprioception & $\begin{array}{l}\text { Reaction to a } \\
\text { stimulus on each } \\
\text { body side }\end{array}$ & $\begin{array}{l}\text { Normal on } \\
\text { both sides }\end{array}$ & $\begin{array}{l}\text { Slowly on one } \\
\text { side }\end{array}$ & $\begin{array}{l}\text { Slowly on both } \\
\text { sides }\end{array}$ & $\begin{array}{l}\text { No on one } \\
\text { side }\end{array}$ & $\begin{array}{l}\text { No on both } \\
\text { sides }\end{array}$ & - & - & $0-4$ & 0 \\
\hline $\begin{array}{l}\text { Vibrissae } \\
\quad \text { proprioception }\end{array}$ & $\begin{array}{l}\text { Turning head after } \\
\text { touching vibrissae }\end{array}$ & $\begin{array}{l}\text { Equally on } \\
\text { both sides }\end{array}$ & $\begin{array}{l}\text { Slowly on one } \\
\text { side }\end{array}$ & $\begin{array}{l}\text { Slowly on both } \\
\text { sides }\end{array}$ & $\begin{array}{l}\text { None on } \\
\text { one side }\end{array}$ & $\begin{array}{l}\text { None on both } \\
\text { sides }\end{array}$ & - & - & $0-4$ & 0 \\
\hline Consciousness & $\begin{array}{l}\text { Observation of } \\
\text { activity }\end{array}$ & Normal & - & Clouded & - & Lethargic & - & - & $0-4$ & 0 \\
\hline Total neuroscore & & & & & & & & & $0-85$ & $0-4$ \\
\hline
\end{tabular}

Normal ranges were defined as the mean \pm 2 standard deviations of 96 healthy untreated rats. $m H B T$, Modified hole board test.

tive deficits decreased. Fifty percent of the animals survived without any deficits in motor function after 48 minutes of DHCA (95\% confidence interval, 19-63 minutes; Figure 1, $B)$ and without any cognitive impairment after 40 minutes of DHCA (95\% confidence interval, 0-60 minutes; Figure 1, C). With the exception of 3 animals ( 1 in the 60-minute, 1 in the 75-minute, and 1 in the 90-minute DHCA groups), rats demonstrated no alterations in behavior 14 days after 
TABLE 2. Physiologic data during the operative procedure in 6 groups of escalating durations of deep hypothermic circulatory arrest

\begin{tabular}{|c|c|c|c|c|c|c|c|c|}
\hline & $\begin{array}{c}\text { DHCA } \\
\text { duration }\end{array}$ & $\begin{array}{c}\text { Before } \\
\text { CPB }\end{array}$ & $\begin{array}{l}\text { Before } \\
\text { DHCA }\end{array}$ & $\begin{array}{l}\text { After } \\
\text { DHCA }\end{array}$ & CPB end & $\begin{array}{c}\text { After CPB } \\
\text { (1 h) }\end{array}$ & $\begin{array}{c}\text { Time }^{2} \times \\
\text { DHCA }\end{array}$ & Time $^{2}$ \\
\hline \multirow{6}{*}{$\begin{array}{l}\text { Pericranial } \\
\text { temperature }\left({ }^{\circ} \mathrm{C}\right)\end{array}$} & 0 min & $35.8 \pm 0.3$ & $13.9 \pm 0.7$ & $19.1 \pm 1.1$ & $35.8 \pm 0.1$ & $36.7 \pm 0.2$ & \multirow[t]{6}{*}{$P<.02$} & $P<.01$ \\
\hline & $45 \mathrm{~min}$ & $36.0 \pm 0.4$ & $14.9 \pm 0.3$ & $19.5 \pm 0.8$ & $35.9 \pm 0.2$ & $36.4 \pm 0.3$ & & $P<.01$ \\
\hline & $60 \mathrm{~min}$ & $35.9 \pm 0.7$ & $13.9 \pm 1.2$ & $18.9 \pm 2.9$ & $35.4 \pm 0.6$ & $36.4 \pm 0.3$ & & $P<.01$ \\
\hline & $75 \mathrm{~min}$ & $35.1 \pm 0.4$ & $15.5 \pm 0.9$ & $21.2 \pm 0.9$ & $35.8 \pm 0.0$ & $36.6 \pm 0.2$ & & $P<.01$ \\
\hline & $90 \mathrm{~min}$ & $35.2 \pm 0.3$ & $14.3 \pm 0.5$ & $23.1 \pm 0.3$ & $35.8 \pm 0.2$ & $36.7 \pm 0.2$ & & $P<.01$ \\
\hline & $105 \mathrm{~min}$ & $36.5 \pm 0.4$ & $16.2 \pm 0.3$ & $21.5 \pm 1.0$ & $36.1 \pm 0.2$ & $38.4 \pm 0.8^{*}$ & & $P<.01$ \\
\hline \multirow{6}{*}{$\begin{array}{l}\text { Mean arterial pressure } \\
(\mathrm{mm} \mathrm{Hg})\end{array}$} & $0 \mathrm{~min}$ & $84 \pm 2$ & $35 \pm 3$ & $32 \pm 2$ & I & $78 \pm 4$ & \multirow[t]{6}{*}{$P<.03$} & $P<.01$ \\
\hline & $45 \mathrm{~min}$ & $79 \pm 4$ & $32 \pm 1$ & $53 \pm 8$ & & $77 \pm 6$ & & $P<.01$ \\
\hline & $60 \mathrm{~min}$ & $81 \pm 4$ & $38 \pm 4$ & $45 \pm 10$ & & $78 \pm 10$ & & $P<.01$ \\
\hline & $75 \mathrm{~min}$ & $84 \pm 5$ & $34 \pm 2$ & $45 \pm 4$ & & $81 \pm 4$ & & $P<.01$ \\
\hline & $90 \mathrm{~min}$ & $89 \pm 3$ & $33 \pm 2$ & $45 \pm 4$ & & $86 \pm 6$ & & $P<.01$ \\
\hline & $105 \mathrm{~min}$ & $87 \pm 3$ & $37 \pm 2$ & $71 \pm 9 \dagger$ & & $71 \pm 2$ & & $P<.02$ \\
\hline \multirow{6}{*}{$\begin{array}{l}\text { Glucose concentration } \\
\text { (mg/dL) }\end{array}$} & $0 \mathrm{~min}$ & $125 \pm 23$ & $143 \pm 25$ & $187 \pm 38$ & $289 \pm 51$ & $208 \pm 34$ & \multirow[t]{6}{*}{$P<.01$} & NS \\
\hline & $45 \mathrm{~min}$ & $126 \pm 15$ & $139 \pm 12$ & $199 \pm 28$ & $237 \pm 50$ & $158 \pm 18$ & & $P<.04$ \\
\hline & $60 \mathrm{~min}$ & $140 \pm 34$ & $143 \pm 45$ & $252 \pm 39$ & $315 \pm 73$ & $190 \pm 66$ & & $P<.01$ \\
\hline & $75 \mathrm{~min}$ & $135 \pm 16$ & $129 \pm 7$ & $226 \pm 17$ & $307 \pm 32$ & $181 \pm 23$ & & $P<.01$ \\
\hline & $90 \mathrm{~min}$ & $124 \pm 10$ & $138 \pm 8$ & $284 \pm 24$ & $344 \pm 19$ & $141 \pm 18$ & & $P<.01$ \\
\hline & $105 \mathrm{~min}$ & $103 \pm 7$ & $160 \pm 9$ & $291 \pm 48$ & $291 \pm 33$ & $77 \pm 10 \dagger$, II & & $P<.01$ \\
\hline \multirow[t]{6}{*}{$\mathrm{PaO}_{2}(\mathrm{~mm} \mathrm{Hg})$} & $0 \mathrm{~min}$ & $215 \pm 20$ & $499 \pm 18$ & $426 \pm 23$ & $338 \pm 25$ & $189 \pm 32$ & \multirow[t]{6}{*}{ NS } & $P<.01$ \\
\hline & $45 \mathrm{~min}$ & $161 \pm 14$ & $486 \pm 16$ & $401 \pm 22$ & $357 \pm 15$ & $188 \pm 26$ & & $P<.01$ \\
\hline & $60 \mathrm{~min}$ & $194 \pm 42$ & $512 \pm 62$ & $453 \pm 51$ & $329 \pm 42$ & $157 \pm 41$ & & $P<.01$ \\
\hline & $75 \mathrm{~min}$ & $171 \pm 20$ & $496 \pm 35$ & $429 \pm 28$ & $345 \pm 22$ & $171 \pm 15$ & & $P<.01$ \\
\hline & $90 \mathrm{~min}$ & $192 \pm 17$ & $463 \pm 37$ & $407 \pm 20$ & $346 \pm 22$ & $215 \pm 34$ & & $P<.01$ \\
\hline & $105 \min$ & $237 \pm 32$ & $462 \pm 27$ & $423 \pm 17$ & $398 \pm 27$ & $112 \pm 9$ & & $P<.01$ \\
\hline
\end{tabular}

Some values were controlled within defined physiologic ranges at certain times, and therefore they are not presented and statistically analyzed. $I$, Mean arterial pressure was controlled above $50 \mathrm{~mm} \mathrm{Hg}$ by means of norepinephrine infusion at mean infusion rates of $2 \pm 1 \mu \mathrm{g} \cdot \mathrm{kg}^{-1} \cdot \mathrm{min}^{-1}(0$-minute DHCA group), $2 \pm 1 \mu \mathrm{g} \cdot \mathrm{kg}^{-1} \cdot \mathrm{min}^{-1}$ (45-minute DHCA group), $3 \pm 2 \mu \mathrm{g} \cdot \mathrm{kg}^{-1} \cdot \mathrm{min}^{-1}$ (60-minute DHCA group), $3 \pm 1 \mu \mathrm{g} \cdot \mathrm{kg}^{-1} \cdot \mathrm{min}^{-1}$ (75-minute DHCA group), $6 \pm 1 \mu \mathrm{g} \cdot \mathrm{kg}^{-1} \cdot \mathrm{min}^{-1}$ (90-minute DHCA group), and $16 \pm 4 \mu \mathrm{g} \cdot \mathrm{kg}^{-1} \cdot \min ^{-1}(* 105$-minute DHCA group). II, serum glucose concentration was controlled above $60 \mathrm{mg} / \mathrm{dL}$ by means of glucose infusion of $100 \pm 58 \mathrm{mg}$ per rat; $\left({ }^{*} 105\right.$-minute DHCA group). After DHCA, base excess was controlled between -3 and $3 \mathrm{mmol} / \mathrm{L}$ by using total doses of $\mathrm{NaHCO}_{3}$ of $0 \pm 0 \mathrm{mmol} / \mathrm{L}$ (0-minute DHCA group), $28 \pm 8 \mathrm{mmol} / \mathrm{L}$ (†45-minute DHCA group), $53 \pm 29 \mathrm{mmol} / \mathrm{L}$ ( $+60-\mathrm{minute}$ DHCA group), $80 \pm 12 \mathrm{mmol} / \mathrm{L}$ (†75-minute DHCA group), $99 \pm 3 \mathrm{mmol} / \mathrm{L}$ (†90-minute DHCA group), and $265 \pm 21 \mathrm{mmol} / \mathrm{L}$ (*105-minute DHCA group). Data are presented as means \pm SEM. DHCA, Deep hypothermic circulatory arrest; $C P B$, cardiopulmonary bypass; $N S$, not significant. ${ }^{*} P<.05$ compared with $0,45,60,75$, and 90 minutes; $\uparrow P<.05$ compared with 0 -minute DHCA group.

DHCA. Sensory function was not impaired in any of the surviving rats at postoperative day 12 .

Neurologic outcome, including motor, cognitive, sensory, and behavioral function, at postoperative days 12 or 14 was not correlated with the histologic score $(r=0.51$, Figure 2). However, distinct histologic changes were evident in the hippocampus and the cerebellar vermis (Figure 3).

\section{Discussion}

This study presents a novel long-term recovery model of DHCA in the rat on the basis of a recently introduced and improved rodent model of complete CPB. ${ }^{6,10}$ Long-term recovery of rats exposed to DHCA was accomplished, with survival depending on DHCA duration. Motor, as well as neurocognitive, performance was impaired after clinically relevant durations of DHCA up to 60 minutes and persisted for at least 14 days. At this time, the overall functional outcome was not correlated to the histopathologic findings.
The current model does not represent the primary description of DHCA in the rat. Mendler and colleagues ${ }^{11}$ pioneered in this field some 30 years ago with the original report of partial $\mathrm{CPB}$ in deep hypothermia in the rat. Because of marked improvement of technology, this original work appears to be less applicable to the current clinical situation. Thirty years later, Kawaguchi and associates ${ }^{12}$ described a technically advanced rat model of DHCA. This work represents a major step toward a clinically relevant long-term recovery model of DHCA in rodents. However, CPB flows of 30 to $36 \mathrm{~mL} \cdot \mathrm{kg}^{-1} \cdot \mathrm{min}^{-1}$ did not exceed one fifth of the normal cardiac output in the rat, and continued ventilation was required to sustain sufficient oxygenation. In the current study long-term survival was accomplished by miniaturization of the CPB circuit and incorporation of a recently developed rat oxygenator. The proportion of prime volume $(10 \mathrm{~mL})$ to rat total blood volume $(25 \mathrm{~mL})$ is similar to that commonly used in human subjects $(2 \mathrm{~L}$ of prime 
1A)

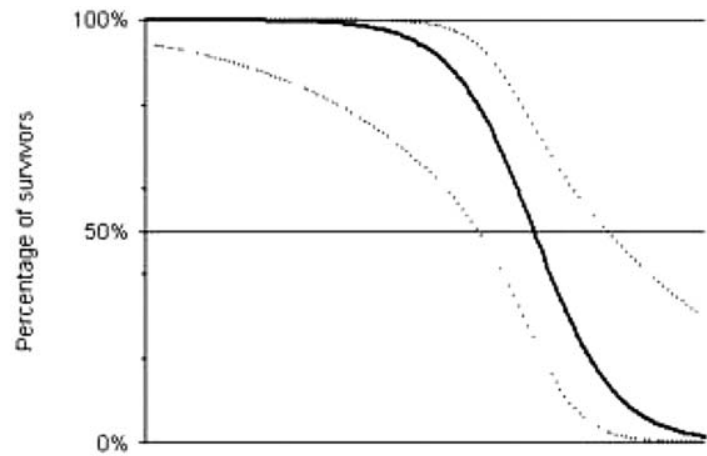

1B)

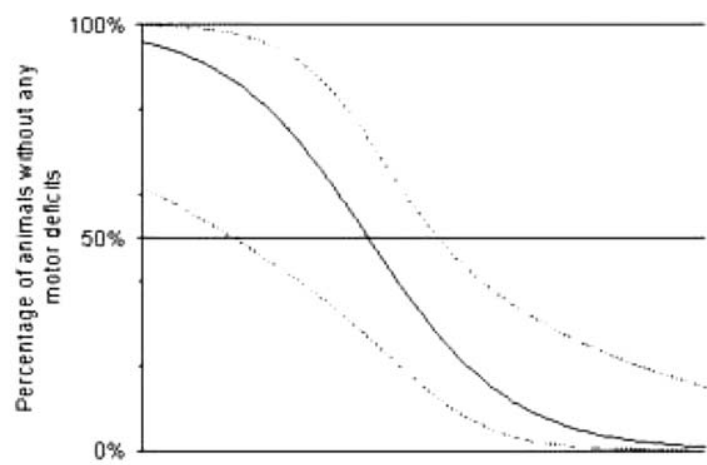

1C)

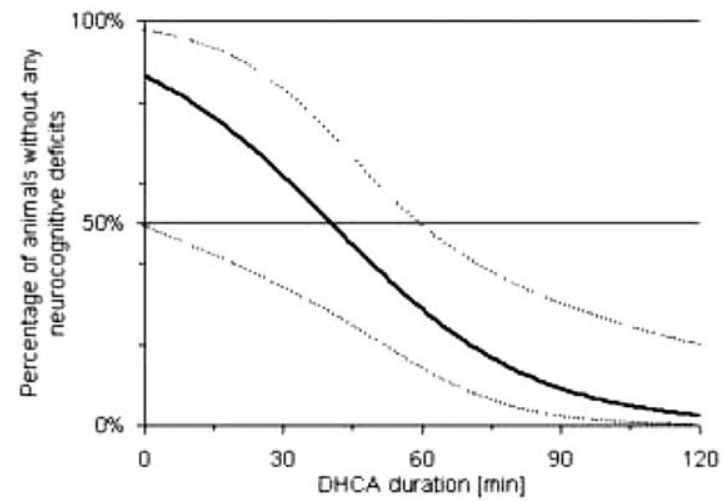

Figure 1. Survival, motor, and neurocognitive function after escalating durations of deep hypothermic circulatory arrest (DHCA). Logistic regressions demonstrate a reciprocal relation between survival (A), motor (B), or neurocognitive (C) outcome and the duration of DHCA (mean value $\pm 95 \%$ confidence interval).

vs $5 \mathrm{~L}$ of blood volume). Reducing the prime to $10 \mathrm{~mL}$ allowed the conduct of CPB and DHCA without blood transfusion at hematocrit values commonly seen in clinical practice. Furthermore, the model allows CPB flows equivalent to normal cardiac output in the rat $\left(160-180 \mathrm{~mL} \cdot \mathrm{kg}^{-1} \cdot \mathrm{min}^{-1}\right)^{13}$ and clinically used CPB flows $\left(100-150 \mathrm{~mL} \cdot \mathrm{kg}^{-1} \cdot \mathrm{min}^{-1}\right)$, resulting in sufficient oxygenation of the nonventilated animals.

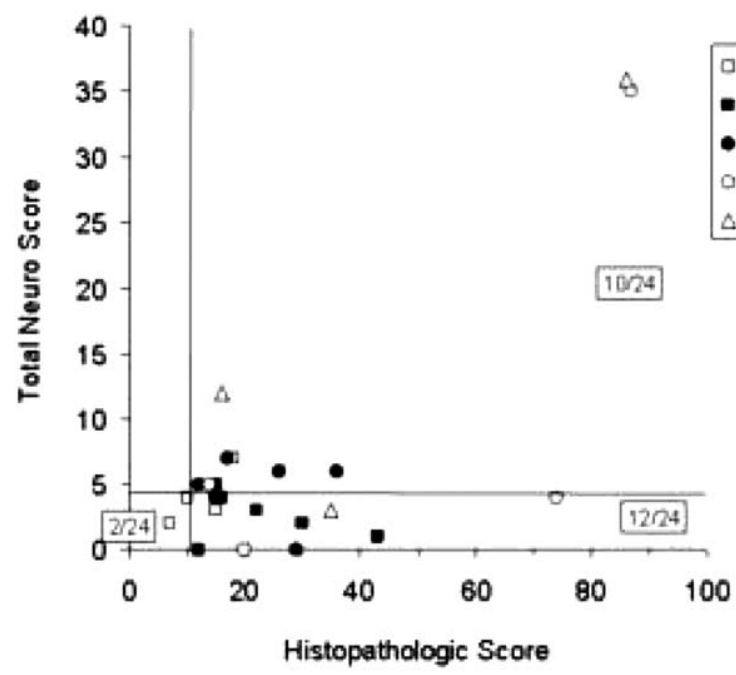

Figure 2. Correlation between cerebral functional outcome and histopathologic findings. Spearman rank correlation revealed no correlation between the functional and the histologic score $(r=$ 0.51 ). The normal range for the total neuroscore (Table 1) is between 0 and 4 (horizontal line), and the normal range for the histopathology is between 0 and 12 (vertical line). Therefore 2 of 24 animals show normal values for both functional and histologic score. Ten animals demonstrate impaired cerebral function with a histologic score beyond normal ranges. Twelve animals show pathologic findings in histology, although the functional outcome was within normal ranges.

In the current study, extended DHCA times (90-105 minutes) beyond the duration of what is commonly required in clinical practice caused severe cerebral injury. Reducing DHCA duration to 75 minutes allowed survival of the animals, initially without signs of severe cerebral injury. However, these rats later had end-organ dysfunction. Further reduction of the DHCA to 60 minutes or less resulted in excellent long-term survival, with morbidity confined to neurologic deficits.

In human subjects the duration of DHCA is considered to be an important risk factor for adverse cerebral outcomes after the repair of congenital heart disease. However, the upper safe limit of DHCA is still discussed controversially or might not even exist. ${ }^{14-17}$ Recent large-animal studies had to use DHCA durations of at least 80 to 120 minutes to demonstrate neurologic deficits. Because these DHCA durations are beyond customary clinical practice, ${ }^{12,18,19}$ the results of those studies might not be applicable to the clinical scenario. In contrast, the current study demonstrates that clinically relevant DHCA durations of up to 60 minutes result in detectable motor, as well as neurocognitive, impairments that remain for at least 2 weeks.

Cerebral function was evaluated by a large test battery, including commonly used motor and sensory tests, as well 


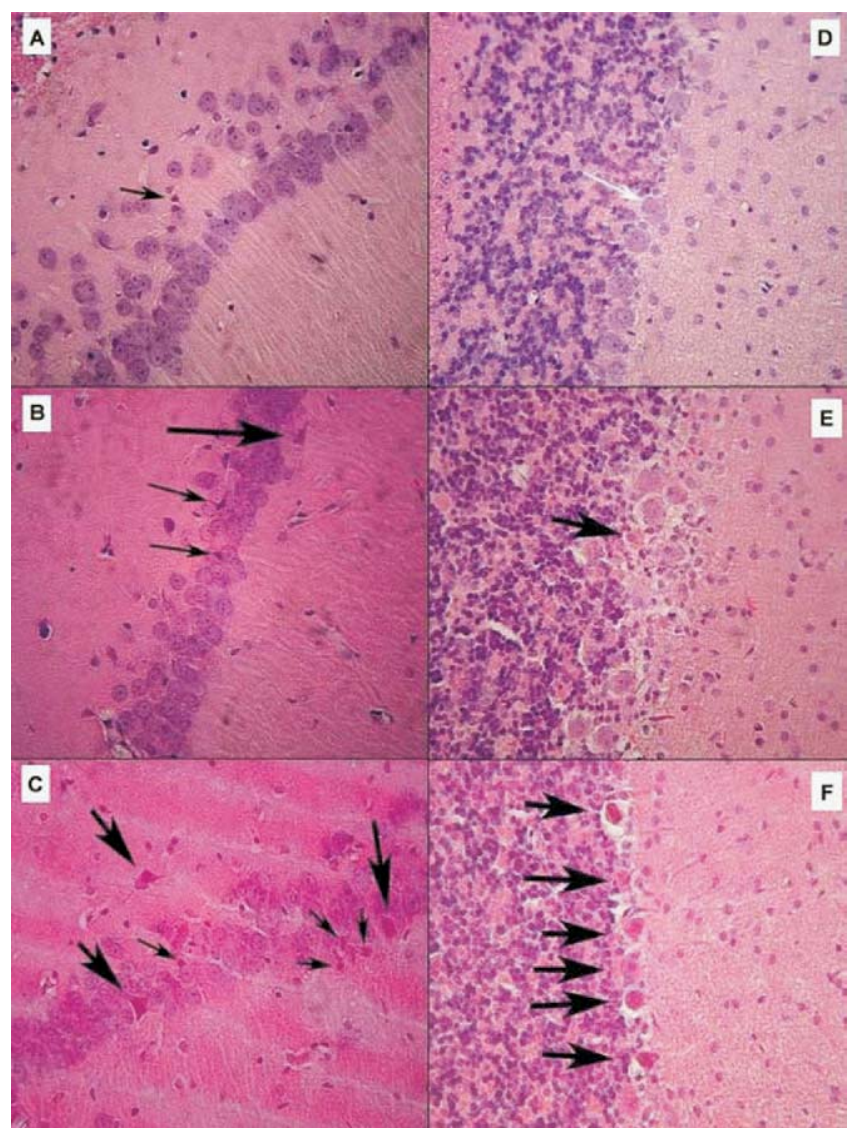

Figure 3. Histologic findings: representative coronal brain sections of the hippocampus and the cerebellar vermis that were stained with hematoxylin and eosin and visualized at a high-field magnification of $\mathbf{4 4 0}$ times. Both areas contain neurons that are highly susceptible for hypoxia (images of hippocampus area CA1, A-C; images of the cerebellar vermis, D-E). A, Sham-operated animal with a normal histologic score. One incidental shrunken neuron with pyknotic nucleus and highly eosinophilic cytoplasm is visible (dark neuron; small arrow). B, Animal after $\mathbf{4 5}$ minutes of deep hypothermic circulatory arrest with a histologic score of 30. Three damaged neurons were detected, 2 resembling dark neurons (see above) and 1 with moderate eosinophilic cytoplasm and condensed substance of nissl (chromatolysis; large arrow). C, Animal after 90 minutes of deep hypothermic circulatory arrest and a histologic score of 86 . The image shows an increased number of injured neurons, with a mixture of irreversible damaged dark neurons (small arrows) and swollen cells with marked eosinophilic cytoplasm and chromatolysis (large arrows). D, Same animal as in panel A. The Purkinje cells (white arrow) appear to be normal and without any signs of hypoxic alteration. E, Same animal as in panel B. The arrow points toward a single Purkinje cell with chromatolysis and eosinophilic cytoplasm. $\mathrm{F}$, Same animal as in panel $\mathrm{C}$. The image shows marked hypoxic changes of most Purkinje cells (large arrow). as the mHBT. ${ }^{7-9,20,21}$ The latter represents a unique task to investigate a variety of cognitive, behavioral, and finemotor parameters in a single test. It allows a comprehensive and detailed evaluation of cerebral outcome in rats. Of note, the functional score obtained by using this test battery did not correlate with the histologic findings 14 days after DHCA. This is in accordance with other studies of cerebral injury showing discrepancies between functional and histologic outcomes when other frequently used neurologic and cognitive tests were applied. ${ }^{22-24}$ Of particular interest, several animals in the current study showed severe histologic damage without demonstrating functional deficits 14 days after DHCA. These results deserve further discussion. Enhanced neurogenesis as a response to cerebral injury with an improved functional outcome in animals with stimulated neurogenesis has been introduced as a potential mechanism to allow for functional recovery. ${ }^{25,26}$ Alternatively, the training effect of the animals from repetitive testing might have improved function over time. This could explain why overall functional outcome on day 12 was considerably better than expected given the histologic damage detected. Comparable findings were recently published, with improved performance of animals on the rotarod during the first days after cerebral ischemia without correlation to infarct volume. $^{24}$

Even though this rodent model of CPB and DHCA was established to mimic clinical standards as closely as possible, some important limitations remain. Median sternotomy, direct cardiac cannulation, and surgical intervention were not performed to allow long-term survival of the animals.

There are several reasons why an appropriate disease model of DHCA in the rat might be considered a realistic alternative to use of large-animal models. First, the current model is far less expensive and more accessible to many potential investigators. Second, the current model might be used to specifically examine the effect of various flow patterns, different temperature regimens, and anesthetics on cerebral and other organ dysfunction after DHCA. Furthermore, because molecular pathways are suspected mechanisms behind cerebral dysfunction associated with CPB and DHCA, the availability of various techniques of cellular and molecular biology significantly add to the value of this model.

In summary, this study presents a novel long-term recovery model of DHCA in the rat. Neurologic, cognitive, and histologic deficits were detected after clinically relevant DHCA durations. This experimental setup appears to be a suitable disease model to further elucidate mechanisms associated with adverse cerebral outcome after cardiac surgery and DHCA and to investigate potential neuroprotective strategies.

\section{References}

1. Limperopoulos C, Majnemer A, Shevell MI, Rohlicek C, Rosenblatt B, Tchervenkov C, et al. Predictors of developmental disabilities after 
open heart surgery in young children with congenital heart defects. J Pediatr. 2002;141:51-8.

2. Bellinger DC, Jonas RA, Rappaport LA, Wypij D, Wernovsky G, Kuban KC, et al. Developmental and neurologic status of children after heart surgery with hypothermic circulatory arrest or low-flow cardiopulmonary bypass. $N$ Engl J Med. 1995;332:549-55.

3. Hovels-Gurich HH, Seghaye MC, Dabritz S, Messmer BJ, von Bernuth G. Cognitive and motor development in preschool and schoolaged children after neonatal arterial switch operation. J Thorac Cardiovasc Surg. 1997;114:578-85.

4. Galli KK, Zimmerman RA, Jarvik GP, Wernovsky G, Kuypers MK, Clancy RR, et al. Periventricular leukomalacia is common after neonatal cardiac surgery. J Thorac Cardiovasc Surg. 2004;127:692-704.

5. Hindman BJ, Todd MM. Improving neurologic outcome after cardiac surgery. Anesthesiology. 1999;90:1243-7.

6. Mackensen GB, Sato Y, Nellgard B, Pineda J, Newman MF, Warner DS, et al. Cardiopulmonary bypass induces neurologic and neurocognitive dysfunction in the rat. Anesthesiology. 2001;95:1485-91.

7. Combs DJ, D'Alecy LG. Motor performance in rats exposed to severe forebrain ischemia: effect of fasting and 1,3-butanediol. Stroke. 1987; 18:503-11.

8. Ohl F, Roedel A, Storch C, Holsboer F, Landgraf R. Cognitive performance in rats differing in their inborn anxiety. Behav Neurosci. 2002;116:464-71.

9. Ohl F, Holsboer F, Landgraf R. The modified hole board as a differential screen for behavior in rodents. Behav Res Methods Instrum Comput. 2001;33:392-7.

10. Jungwirth B, Kochs E, Mackensen GB. Development of a small volume oxygenator: an essential improvement to a model of cardiopulmonary bypass in the rat. Anesth Analg. abstract 2003;SCA 72.

11. Mendler N, Reulen H, Brendel W. Cold swelling and energy metabolism in the hypothermic brain of rats and dogs. In: South F, Hannon J, Willis J, Pengelley E, Alpert N, South F, et al. Hibernation and hypothermia, perspective and challenges. Amsterdam: Elsevier;1972. p. $167-90$.

12. Kawaguchi AT, Yamano M, Naritomi H, Ishibashi-Ueda H, Yamatodani A, Koide S. Neurological function after deep hypothermic circulatory arrest in the rat. Circulation. 1998;98(suppl II):II385-90.

13. Li SG, Randall DC, Brown DR. Roles of cardiac output and peripheral resistance in mediating blood pressure response to stress in rats. Am J Physiol. 1998;274:R1065-9.

14. Wypij D, Newburger JW, Rappaport LA, du Plessis AJ, Jonas RA, Wernovsky G, et al. The effect of duration of deep hypothermic circulatory arrest in infant heart surgery on late neurodevelopment: the
Boston Circulatory Arrest Trial. J Thorac Cardiovasc Surg. 2003;126:1397-403.

15. Oates RK, Simpson JM, Turnbull JA, Cartmill TB. The relationship between intelligence and duration of circulatory arrest with deep hypothermia. J Thorac Cardiovasc Surg. 1995;110:786-92.

16. Newburger JW, Jonas RA, Wernovsky G, Wypij D, Hickey PR, Kuban $\mathrm{KC}$, et al. A comparison of the perioperative neurologic effects of hypothermic circulatory arrest versus low-flow cardiopulmonary bypass in infant heart surgery. N Engl J Med. 1993;329:1057-64.

17. Kirkham FJ. Recognition and prevention of neurological complications in pediatric cardiac surgery. Pediatr Cardiol. 1998;19:331-45.

18. Kurth CD, Priestley M, Golden J, McCann J, Raghupathi R. Regional patterns of neuronal death after deep hypothermic circulatory arrest in newborn pigs. J Thorac Cardiovasc Surg. 1999; 118:1068-77.

19. Nollert G, Nagashima M, Bucerius J, Shin'oka T, Lidov HG, du Plessis A, et al. Oxygenation strategy and neurologic damage after deep hypothermic circulatory arrest. II. hypoxic versus free radical injury. J Thorac Cardiovasc Surg. 1999;117:1172-9.

20. Ohl F, Toschi N, Wigger A, Henniger MS, Landgraf R. Dimensions of emotionality in a rat model of innate anxiety. Behav Neurosci. 2001; 115:429-36.

21. Ohl F, Sillaber I, Binder E, Keck ME, Holsboer F. Differential analysis of behavior and diazepam-induced alterations in C57BL/6N and BALB/c mice using the modified hole board test. J Psychiatr Res. 2001;35:147-54

22. Bayona NA, Gelb AW, Jiang Z, Wilson JX, Urquhart BL, Cechetto DF. Propofol neuroprotection in cerebral ischemia and its effects on lowmolecular-weight antioxidants and skilled motor tasks. Anesthesiology. 2004;100:1151-9.

23. Reglodi D, Tamas A, Lengvari I. Examination of sensorimotor performance following middle cerebral artery occlusion in rats. Brain Res Bull. 2003;59:459-66.

24. Zausinger S, Hungerhuber E, Baethmann A, Reulen H, SchmidElsaesser R. Neurological impairment in rats after transient middle cerebral artery occlusion: a comparative study under various treatment paradigms. Brain Res. 2000;863:94-105.

25. Nakatomi H, Kuriu T, Okabe S, Yamamoto S, Hatano O, Kawahara N, et al. Regeneration of hippocampal pyramidal neurons after ischemic brain injury by recruitment of endogenous neural progenitors. Cell. 2002;110:429-41.

26. Felling RJ, Levison SW. Enhanced neurogenesis following stroke. J Neurosci Res. 2003;73:277-83. 